\title{
UNA MIRADA CIENTÍFICA A LA FRONTERA: CALIFORNIA EN LA CENTURIA ILUSTRADA
}

\author{
Dr. Salvador Bernabéu Albert \\ (EEHC, CSIC)
}

\section{1772: una ópera y dos crónicas californianas ${ }^{1}$}

Se abre el telón. Estamos en la Ciudad Eterna, un 22 de febrero de 1772. Durante los festejos del Carnaval, el teatro Capranica presenta la última ópera del autor más famoso del momento, el maestro Niccolò Piccinni (Bari, 1728-París, 1800). El título de la obra es L'Americano; su creador la ha calificado como Operetta giocosa, Intermezzo per musica e farsetta ${ }^{2}$. El decorado representa un paisaje costero. Un lejano navío y una barca junto a la playa simbolizan la llegada de un viajero. En efecto, después de tres años de periplo por América y de cruzar dos veces el Ecuador, el caballero (cavaliere) Lisandro desembarca en su mansión, cercana a Livorno. Allí se encuentra con su enamorada, doña Aurora, y con una bella pastora Ilamada Silvia. El diálogo musical entre los tres da paso a la primera sorpresa de la obra. Lisandro le comunica a su amada que ha raptado a un joven americano, nacido en la península de California, quien en esos momentos está haciendo vestir a la europea. El recitativo siguiente dice así:

"Cavalieri: De uomini più graziosi

Di noi. Uno en ho meco,

Nato nella penisola di California...

1. El artículo se inscribe en el proyecto "Las fronteras y sus ciudades: herencias, experiencias y mestizajes en los márgenes del imperio hispánico (s. XVI-XVIII)", del Ministerio de Educación y Ciencia (HUM2007-64126).

2. La primera grabación mundial se realizó en el Palazzo Ducale de Martina Franca, Italia, los días 25-27 de julio de 1996. Un año después apareció en CD en el sello "Dynamic". La Orchestra Internazionale d'Italia estuvo dirigida por el maestro Eric Hull, siendo sus intérpretes Simon Edwards, Patrizia Ciofi, Domenico Colaianni y Giovanna Donadini. Se trata de la única ópera que conozco protagonizada por un indio californio. 


\begin{abstract}
Aurora: Con disprezzo
Oibò che brutto nome! California...
\end{abstract}

Cavalieri: Se quello è il nome suo,

Se si chiama così... Inquietato

Dite ai Geografi che lo mutino. O bella!

Sì Signora, trovai nella penisola di California (...)

Aurora: E poi non s'ha da dir che siete un matto!

Riportar alla patria un barbaro,

un selvaggio Americano,

Perchè ci mangi tutti...

Cavalieri: Inquietato Questo barbaro,

Quest'idiota selvaggio

V'insegnerà cospetto...

Sì, sì, v'insegnerà

Quel che voi non sapete:

Pria vedetelo almen, poi decidete".

El californiano que tanto miedo le produce a Doña Aurora (la cual califica a California de brutto nome y le reprende a Lisandro el traer a la patria un bárbaro, un salvaje americano, para que se los coma a todos) se llama Villotto y servirá al autor para mostrar, con su salvajismo, las contradicciones de las costumbres civilizadas del Viejo Mundo. De inspiración volteriana, la función pone en escena una cuestión muy debatida en esos momentos: la superioridad del europeo frente al indio americano y el derecho de imponerles la civilización a la fuerza o por medio de la esclavitud. El libreto de L'Americano (también conocido como L'Americano Incivilito y L'Americano Ingentilico) es de Angelo Longi, del que desconozco todo. Pero lo importante de la ópera es la referencia a la península de California en la Europa de los setenta de la centuria ilustrada, así como la inserción y escritura de la historia bajacaliforniana en medio de la polémica de los autores europeos sobre la naturaleza y el hombre americano, conocida como la disputa del Nuevo Mundo.

El libreto operístico califica al californiano de bárbaro, salvaje americano, idiota selvático y bruto. La ópera se estrenó, recordémoslo de nuevo, en Roma en 1772. Pues bien, los mismos calificativos los encontraremos en otra obra editada ese mismo año en otro punto de Europa: la ciudad de Mannheim, en Alemania. Se trata de la famosa Nachrichten von der Umerikanischen Halbinsel Californien (Noticias de la península americana de California), del jesuita expulso Juan Jacobo Baegert. "Por regla general -escribe el misionero-, puede decirse de los californios que son tontos, torpes, toscos, sucios, insolentes, ingratos, mentirosos, pillos, perezosos en extremo, grandes habladores y, en cuanto a su inteligencia y actividades, como quien dice, niños hasta la tumba; que son gente desorientada, desprevenida, irreflexiva e irresponsable; gente que para nada 
puede dominarse y que en todo siguen sus instintos naturales, igual a las bestias $^{\prime \prime}$. A pesar de ello, el ignaciano afirma que son hijos de Adán, esto es, seres humanos, aunque en un estado infantil o degenerado. De nuevo, sin embargo, los salvajes californianos servirán al autor para dar una lección a los civilizados europeos ${ }^{4}$. La extrema pobreza de los californianos y la ausencia en la península, su habitat, de cosas que a los europeos les parecían indispensables, demostraba "cómo la naturaleza se conforma con tan poco y cómo con tan poco puede uno mantenerse". En consecuencia, el jesuita dictaminó que la opulencia y la lujuria eran las inventoras de miles de cosas superfluas que impedían que "tantos indigentes podrían y deberían ser alimentados y arropados" ${ }^{5}$. La península, convertida en la antagonista de la distinguida y opulenta Europa, servía a algunos autores para darle una lección de "moralidad".

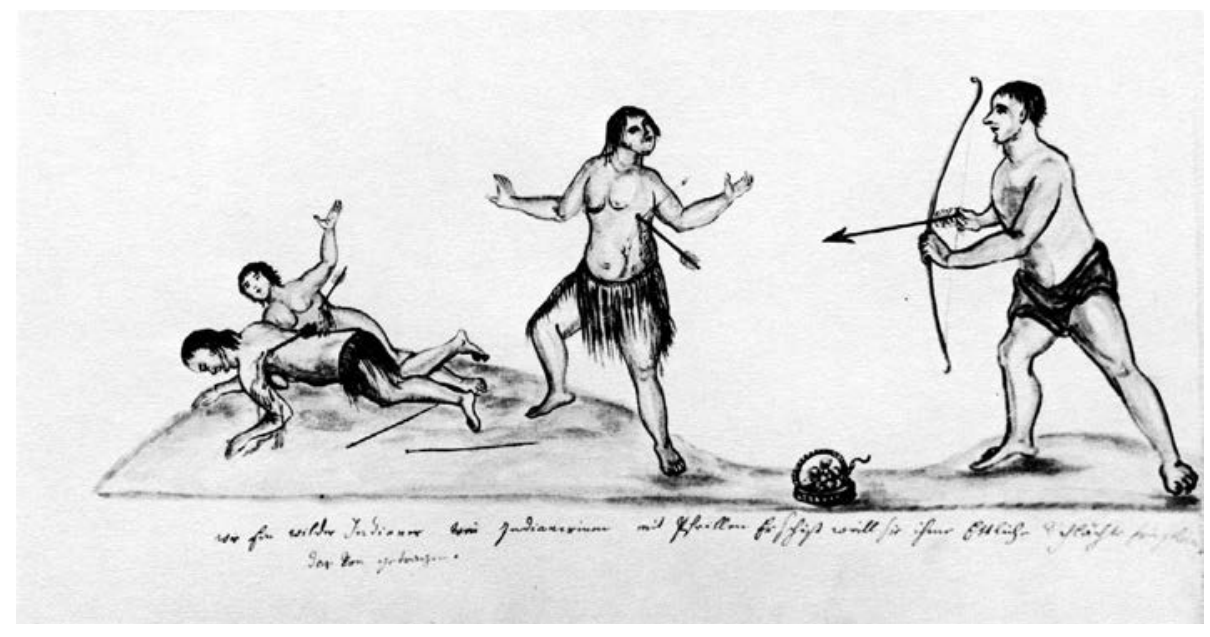

Imagen 1. Indios californios en guerra. Dibujo de Ignacio Tirsch, S.J. Circa 1767. Biblioteca Nacional de Praga.

También en 1772, los lectores europeos leían con ansiedad los sucesos y resultados de una expedición franco-española, dirigida por el eminente astrónomo Chappe d'Auteroche, a Baja California para medir el Paso de Venus por el disco del Sol. Muerto el director de la expedición en la misión de San José del Cabo, situada en el extremo meridional de la península, sus compañeros savants de la

3. Baegert, J. J., Noticias de la península americana de California. México, 1942, p. 109.

4. Sobre el tema, véase el capítulo "El buen salvaje y el mal europeo", del libro de Rojas Mix, M., América imaginaria. Barcelona, 1992, pp. 168-175.

5. Baegert, J. J., Noticias de la península, p. 86. 
Academia de Ciencias de París utilizaron sus conocimientos e influencias para redactar y editar los resultados del viaje en un interesante libro, Voyage en Californie pour l'observation du passage de Venus sur le disque du soleil (París, 1772). Gracias a él, los lectores europeos pudieron conocer cómo era esa lejana frontera, y las dificultades del camino para llegar hasta ella. El volumen, bellamente editado, era un modelo de "obra científica", destinado tanto a homenajear al difunto Chappe d'Auteroche como a dar a conocer los resultados de la expedición francesa. Sin embargo, sus observaciones y juicios sobre Nueva España no fueron siempre ni favorables ni serenos, si bien, al estar contenidos en este prestigioso libro, se convirtieron automáticamente en "científicos".

En resumen, podemos señalar que en la década de los setenta, la península de California logró una popularidad notable en el Viejo Mundo, pero a costa de una reelaboración profunda. California fue vista multitudinariamente, pero a través del espejo europeo, el espejo de la "civilización", el cenit del progreso, la etapa culminante de la historia universal, en relación a la cual se dispondría el resto de los pueblos y de los territorios ultramarinos ${ }^{6}$. Dentro de esta interesada "mirada", California ocuparía un lugar diferente según los autores, pero un lugar siempre falso. El abate italiano Ferdinando Galiani, cínico lector de las novedades editoriales ilustrada, Ilegó a escribir que los indios californios eran, como en general todo ser no civilizado por los blancos, un verdadero bruto. Pero no contento con ello, añadió que los indios ni siquiera llegaban a la condición de hombres, sino que eran: "le plus espiègle, le plus malin et le plus adroit des singes" (el más travieso, el más maligno y el más astuto de los monos) ${ }^{7}$.

\section{Las luces sobre California: un balance contradictorio}

El jesuita italiano José María Salvatierra fundó la primera misión permanente en 1697 con el nombre de Nuestra Señora de Loreto tras vencer numerosos obstáculos tanto dentro como fuera de la Compañía de Jesús. Las autoridades reales no querían aportar más caudales para una conquista que se resistía y los directores provinciales ignacianos temieron perder el crédito de la Compañía e involucrarla en una difícil y costosa misión que necesitaba de varios padres, muchos soldados y veloces barcos para abastecerla durante los primeros años. Además, a finales del siglo XVII se había generalizado una imagen muy negativa en la sociedad novohispana: tras varios siglos de tentativas se rumoreaba que la península era inconquistable ${ }^{8}$.

6. Lüsebrink, H.-J., "Civilización", Ferrone, D. y Roche, D. (eds.), Diccionario Histórico de la llustración. Madrid, 1998, pp. 148-154.

7. Citado por Gerbi, A., La disputa del Nuevo Mundo. Historia de una polémica, 17501900. México, 1982, p. 154.

8. "Y según eran repetidas las experiencias de tantos años, llegaron a declarar por inconquistables las Californias los dos Señores Fiscales de las Audiencias de Mexico, y Guadalaxara: 
La autorización virreinal para entrar en California, rubricada por el virrey José Sarmiento de Valladares, marqués de Moctezuma, que gobernó entre 1696 y 1701 , fue otorgada finalmente al padre José María Salvatierra ${ }^{9}$ tras varias peticiones, pero condicionada a la no intervención económica de la Corona en la empresa. Los padres debían tomar posesión en nombre del soberano, pero financiando la conquista espiritual con limosnas y donativos particulares. Esta dejación de las responsabilidades del monarca, que estaba obligado por las bulas alejandrinas a evangelizar el Nuevo Mundo, sería recompensada con una serie de prerrogativas para la nueva misión ignaciana: autoridad sobre los soldados, poder para nombrar o revocar al capitán, control de los pobladores, monopolio sobre los barcos de transporte y prohibición del rescate de perlas ${ }^{10}$. En consecuencia, los padres se opusieron a cualquier novedad que se introdujese en su península, obstaculizando la fundación de pueblos y reales mineros durante los setenta años que estuvieron en ella. No estaban dispuestos a compartir el territorio misional con otros colonos ni a convivir con más proyectos que los propios. El sueño del misionero de tener un grupo de indígenas con el que trabajar en la cristianización, sin la presencia de extraños, se había cumplido. Se habla de construir una nueva comunidad a imagen de las primitivas cristianas ${ }^{11}$. El 25 de mayo de 1705, Salvatierra, que había sido nombrado provincial de la Nueva España, escribió un memorial al virrey duque de Alburquerque en el que defendió todos los privilegios, admitiendo que la tierra no permitía vecinos españoles por su aspereza.

el primero en catorce de Marzo del año de ochenta y seis, y en diez y siete de Abril del año de ochenta y nueve: y el segundo en onze de Marzo del año de noventa y uno". Venegas, M., Empressas Apostólicas de los padres misioneros de la Compañía de Jesús, de la provincia de Nueva España, en Obras Californianas del Padre Miguel Venegas, S. J. Tomo IV. La Paz, 1979, párrafo 167. Después de la entrada de Isidro de Atondo: "eran mal recibidas peticiones sobre la prosecución de esta conquista, reputada ya por impossible" (párrafo 177).

9. El padre Juan María de Salvatierra nació en Milán (Italia) el 15 de noviembre de 1648 en el seno de una familia noble española. Ingresó en la Compañía de Jesús y marchó a Nueva España en 1675, donde impulsó la evangelización californiana. Fundó la misión de Nuestra Señora de Loreto en 1697 y realizó numerosos reconocimientos del territorio peninsular. Además de su decisiva intervención en la colonización de California, Salvatierra fue rector del Colegio Jesuita de Guadalajara (1693), del Colegio-Seminario de Tepozotlán (1696) y provincial de la Nueva España (1704). Murió el 18 de julio de 1717 en Guadalajara (Nueva Galicia). Varias de sus cartas pueden consultarse en Sánchez Vázquez, L., Salvatierra. 300 años, Mexicali, 1997; y en Del Río, I. (ed.), La Fundación de la California Jesuítica. Siete cartas de Juan María de Salvatierra, S. J. (1697-1699). La Paz, 1997.

10. Los estudios más completos de la California jesuítica son Crosby, H. W., Antigua California. Mission and Colony on the Peninsula Frontier, 1697-1768. Albuquerque, 1994, y Del Río, I., El Régimen Jesuítico de la Antigua California. México, 2003. Sobre la fama de las perlas, véase Bernabéu Albert, S., "Perlas para la Reina. Aportaciones al estudio de la industria perlífera durante la colonia (1797-1814)", Estudios de Historia Novohispana, 15 (1995), pp. 129-158.

11. Del Río, I., "Ambigüedades y contradicciones de un régimen de excepción: los jesuitas y el gobierno de la provincia misional de California", Negro, S. y Marzal, M., S. J., Un reino en la frontera: Las misiones jesuitas en la América colonial. Lima, 1999, pp. 97-113. 
La delegación de autoridad a favor de los ignacianos, que hay que enmarcar en los años finales de la dinastía de los Austrias, pronto sería incómoda tanto para la Compañía como para los funcionarios reales. Para estos últimos, porque la nueva dinastía potenció el centralismo, la llegada de colonos a las fronteras, el tráfico comercial, la puesta en utilidad de los territorios y el freno de los privilegios de personas, provincias y corporaciones. Y para los jesuitas, porque las expectativas de Salvatierra de reunir extraordinarias sumas de dineros de particulares (los famosos bienhechores, cuyos donativos se agruparon posteriormente en el Fondo Piadoso de las Californias) no se cumplieron, teniendo que mantenerse con grandes carencias, con unos barcos frágiles y en medio de la hostilidad de los indígenas. De ahí que pronto se tuviese que acudir a las autoridades en busca de dinero, las cuales demoraron su decisión hasta recibir la aprobación del nuevo monarca: Felipe $\mathrm{V}$ de Borbón.

En 1717 murió Salvatierra en Guadalajara cuando se dirigía a México para informar al virrey del estado del nuevo campo misional. Hasta entonces se habían fundado cinco misiones: Nuestra Señora de Loreto Conchó (1697), San Francisco Javier de Biaundó (1699), San Juan Bautista de Ligüí o Malibat (1705), Santa Rosalía de Mulegé (1705) y San José de Comundú (1708), todas ellas en el centro de la península. Entonces se planteó el reto de seguir fundando hacia el prometedor norte, pero sin olvidar la ocupación del extremo sur peninsular con varias finalidades: primero, convertir a los indios de aquellos rumbos, que habían dado repetidas pruebas de ser contrarios a la presencia de misioneros; segundo, evitar tener un enemigo en la retaguardia y, por último, para establecer un puerto en donde auxiliar al galeón de Manila tras avistar las costas del Nuevo Mundo. Así, la década de los veinte estuvo dominada por un gran optimismo tanto por parte de los jesuitas como de sus devotos en el virreinato, quienes financiaron hasta siete misiones: tres en los rumbos norteños, bautizadas como La Purísima Concepción de Cadegomó (1720), Nuestra Señora de Guadalupe Huasinapí (1720) y San Ignacio Kadakaamán (1727), y cuatro en el sur, Nuestra Señora del Pilar de la Paz Airapí (1720), Nuestra Señora de los Dolores Apaté (1721), Santiago el Apóstol Aiñiní, también conocida como Santiago de los Coras (1724), y San José del Cabo Añuití (1730). Durante estos años, diversas órdenes reales confirmaron a los ignacianos en sus prerrogativas, aunque una rebelión indígena destruyó las misiones del sur y estuvo a punto de expulsar a los ignacianos, que se refugiaron en Loreto.

Tras superar la crisis, de nuevo comenzaron las fundaciones. A la misión de San Luis Gonzaga Chiriyaqui (1740), le siguieron Santa Gertrudis (1752) y, ya en la década de los sesenta, San Francisco de Borja Adac (1762) y Santa María Cabujakaamung (1767). Esta progresión en la ocupación del territorio fue acompañada de un inquietante aumento de las críticas al sistema excepcional conseguido por los jesuitas en Baja California: para unos, un paraíso lleno de angelitos californianos; para otros, un infierno donde los padres ejercían la más deleznable tiranía. 
El re-descubrimiento durante el siglo XVIII no fue sólo una empresa conquistadora y evangelizadora, defensiva y económica, sino que comportó algo más: la conformación de una imagen de esa nueva identidad, de ese nuevo territorio que, marginal durante largos años, adquirió veloz e inusitada atención por parte de los políticos y los escritores de la Ilustración, sobre todo tras la expulsión de los jesuitas en 1767 de todos los dominios de Carlos III, lo que permitió la llegada de varios científicos peninsulares, novohispanos y extranjeros.

El proceso de conceptualización de la península californiana en el pensamiento europeo (empezando por convertirse en península y desterrar su persistente carácter insular, algo que llevó varias decenas de años) estuvo condicionado por una serie de factores. De una parte, la atención prestada hacia las actividades evangelizadoras de la Iglesia y el sentimiento anti-clerical de buena parte de los dirigentes ilustrados de la segunda mitad del siglo XVIII. Recuérdese, por ejemplo, las críticas de Voltaire y otros pensadores hacia la Compañía de Jesús. De otra parte, la atención concedida por esos mismos dirigentes hacia las fronteras del imperio, que debían convertirse en barreras defensivas y mercados útiles para los productos metropolitanos (lo que implicaba el pacificarlos y poblarlos previamente). Esos fueron los dictámenes del más influyente político del siglo XVIII español, el marqués de Campomanes, para rescatar a California de las garras de los jesuitas, ideas que influyeron directamente en José de Gálvez y en su programa de reformas. Sin embargo, hay que prestar atención también a la elaboración del discurso californiano, pues la redacción de las historias más importantes, escritas por los antiguos misioneros en el exilio alemán e italiano (Baegert, Clavijero, Barco), se realizaron en medio de la polémica y el debate ilustrado sobre la naturaleza y el hombre americano, un debate desarrollado exclusivamente en los países europeos.

Efectivamente, los libros escritos por los jesuitas expatriados (espina dorsal del discurso californiano) salieron en prensas europeas y son herederos en los contenidos y en las formas de las preocupaciones y los modelos ilustrados. Hay una cierta obligación propagandística y defensiva de la labor de los jesuitas, de justificación de sus resultados y de rectificación de las falsedades y errores que circulaban en otros libros anteriormente editados en México y Madrid, como la Noticia de la California de Miguel Venegas (Madrid, 1752). Una de las características comunes a todos ellos es la sublimación de la experiencia directa, la sobrevaloración del testimonio personal o de compañeros muy cercanos, que habrían pasado largos años trabajando y conociendo la naturaleza bajacaliforniana frente a los sabios de gabinete que lanzaban sus errores cómodamente sentados en sus despachos de París o Londres. Por eso son apreciados y leídos los misioneros jesuitas. Pero, además, esos conocimientos debían ser dispuestos conforme a modelos ilustrados, exitosos en su época, que desterraban las intervenciones sobrenaturales y ampliaban las observaciones científicas sobre la naturaleza y el hombre. A esta nueva orientación responde las amputaciones y enmiendas del jesuita español Marco Andrés Burriel al manuscrito original de su 
compañero novohispano Miguel Venegas (Empressas Apostólicas de los padres misioneros de la Compañía de Jesús, de la provincia de Nueva España), Ilegándolo a desvirtuar y ocultar ${ }^{12}$. Un caso más que curioso, pues, aunque Venegas y Burriel nunca pisaron la California, su obra pronto se convirtió en el relato histórico más difundido y reverenciado acerca de la naturaleza y de la conquista espiritual de la lejana península, con sucesivas traducciones al inglés (1759), holandés (1761-1762) y francés (1766-1767).

Otra de las novedades de esta literatura es el aumento de los capítulos dedicados a la historia natural, que brevemente repasaremos en el siguiente apartado. Después, estudiaremos las expediciones ilustradas, tema al que he dedicado varios artículos en los últimos años y que el lector podrá conocer más detenidamente si acude a ellos. En general, estas expediciones son consecuencia del impulso europeo por conocer científicamente el orbe y de la rivalidad internacional por aumentar la nómina de los descubrimientos entre los principales reinos del Viejo Mundo. Pero sus resultados quedaron, en su mayor parte, en los anaqueles de los archivos oficiales, y sólo se han conocido gracias a las ediciones de las últimas décadas. En consecuencia, la historia natural de la Baja California fue conocida durante la llustración gracias -casi exclusivamente- a los misioneros jesuitas, sin que pasaran al gran público las aportaciones de los científicos ilustrados. Sólo modernamente hemos podido reconstruir los esfuerzos y los resultados de las distintas comisiones ilustradas, que resumiremos a continuación.

Llegados a este punto, creo que la Ilustración presenta un balance contradictorio en relación a la península de California: la descubrió y la encubrió a la vez. La política borbónica y la erudición europea en general (sobre todo francesa e italiana) incorporaron a la península en el debate general del hombre y la naturaleza, de la civilización y la barbarie, en los teatros capitalinos y en las tertulias palaciegas, en las editoriales más prestigiosas y en las enciclopedias más populares. El mecenazgo político y el rigor científico patrocinado por los sabios ilustrados permitió conocer mejor el territorio, extrajo sus secretos, cartografió hasta los más pequeños islotes de la costa, abrió nuevos caminos y, en general, incorporó la remota península en los mapas generales y en las enciclopedias más consultadas. Sin embargo, los ilustrados vieron la península a través de los espejos de sus intereses y sus prejuicios, de sus clichés y sus preocupaciones, de sus intereses religiosos o gremiales y su gusto por lo exótico o lo desconocido. Una docena de científicos recorrieron la península, otra media docena más de misioneros gastaron largas jornadas en disponer sus recuerdos y sus conocimientos para enseñar al mundo lo que era su California, una California de papel, pero bastó una mala experiencia real (la de Gálvez) para que la península fuese poco menos que abandonada a su suerte, a la deriva, como una gigantesca balsa de piedra.

12. Sobre Burriel., véase Echánove Tuero, A., La preparación intelectual del P. Andrés Marcos Burriel, S.J. (1731-1750). Madrid-Barcelona, 1971. 


\section{La California natural}

La península de Baja California tuvo un gran interés natural durante el siglo de las Luces. Convertida desde el siglo XVI en la frontera occidental del virreinato de la Nueva España, fue paulatinamente colonizada desde finales del siglo XVII gracias al empeño de tres órdenes religiosas: jesuitas, franciscanos y dominicos, y a los intereses geoestratégicos de las autoridades españolas. Tras la ocupación de la Alta California -a partir de la expedición enviada por el visitador José de Gálvez en 1769-, la árida península fue decayendo en interés hasta entrar en la época independentista en beneficio de los nuevos territorios colonizados del norte.

Poco poblada durante la centuria ilustrada debido a sus condiciones adversas a la colonización, la Baja California fue objeto de sucesivos reconocimientos y exploraciones por parte de los misioneros, los soldados destacados en aquellos parajes y gracias a diversos científicos llegados desde México y desde Europa para conocer las particularidades naturales de la lejana y misteriosa California. Con apenas unas cuantas aldeas de mineros y ganaderos, amén de las misiones y los cuarteles de vigilancia, esta larga península fue un territorio poco propicio para el desarrollo de la ciencia institucionalizada. Sin embargo, varias expediciones científicas la exploraron y recolectaron informaciones sobre sus producciones, completando, así, un notable corpus de noticias sobre su historia natural contendidas en las cartas, relaciones e informes de los misioneros, que nos han dejado valiosos testimonios y una excelente cartografía.

La labor más notable y completa fue realizada por la Compañía de Jesús, quien fundó las primeras misiones de la península. Sus miembros fueron muy activos en la colección de noticias sobre los pueblos indígenas -a los que querían evangelizar- y los parajes que se les encomendaron. Aprovecharon, además, estas tareas para delinear mapas con los que conocer y proyectar su labor civilizadora, lo que les permitió reunir una importante cartografía del virreinato de Nueva España hasta que fueron expulsados por Carlos III en 1767.

Buena parte de los mapas ignacianos están dedicados a los territorios occidentales de México: Nuevo México, Arizona, Sonora, Sinaloa y California, realizándose en este último territorio el hallazgo más notable: la confirmación de su peninsularidad frente a los partidarios de la insularidad. La Compañía señaló con gran exactitud los aspectos orográficos e hidrográficos, por lo que sus mapas fueron muy estimados y se reprodujeron en diversas publicaciones europeas hasta finales del siglo XVIII ${ }^{13}$. Los mapas se levantaron gracias al esfuerzo de padres como Kino, Consag, Nentwig y Linck. El primero levantó sus propios

13. Al respecto, la mejor obra sigue siendo Burrus, E., S.J., La obra cartográfica de la provincia mexicana de la Compañía de Jesús (1567-1767). Madrid, 1967. Del mismo autor, véase el capítulo titulado "Influencia de antiguos jesuitas mexicanos en la geografía y cartografía universal", en el libro La Compañía de Jesús en México. Cuatro siglos de labor cultural (15671972). México, 1972. 
mapas, mientras Consag y Linck proporcionaron a otros jesuitas -como Pedro María Nascimbem y Baegert- los datos para dibujar nuevas cartas de la península bajacaliforniana. La colección cartográfica ignaciana es muy rica, pero me gustaría destacar dos mapas: el elaborado en 1701 por Kino, que demuestra la peninsularidad de Baja California, y el dibujado por el mismo padre en 1710, el más perfecto y completo, en el que adopta una nueva nomenclatura y resume más de treinta años de exploraciones.

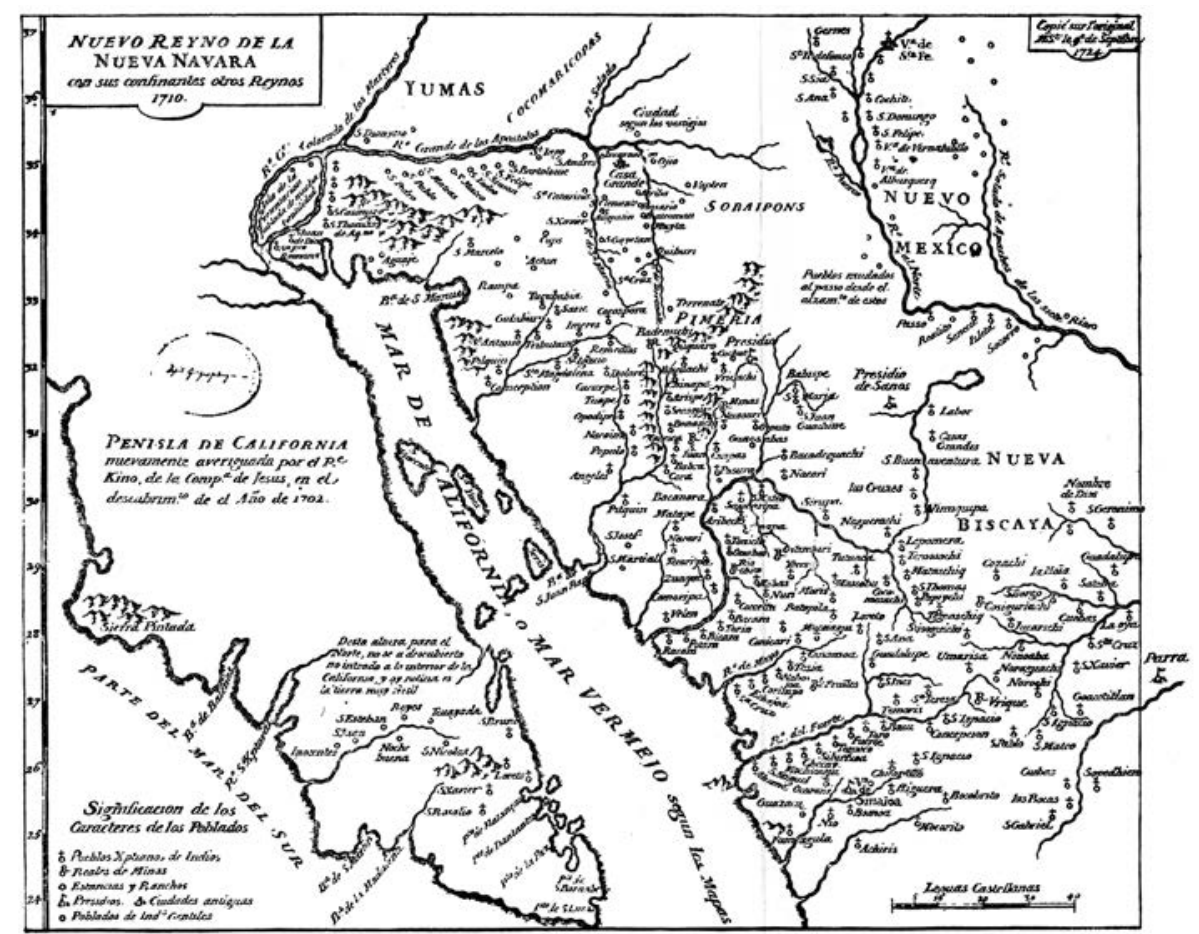

Imagen 2. Mapa del Nuevo Reyno de la Nueva Navarra. Eusebio Francisco Kino, S.J. 1710.

La primera sistematización de la historia natural de la península de Baja California apareció en la ya citada Noticia de la California, del padre Miguel Venegas, publicada en Madrid en 1757 tras ser corregida y ampliada por el también ignaciano Andrés Marcos Burriel ${ }^{14}$. La parte primera de la obra está dedicada a

14. Venegas, M., Noticia de la California y de su conquista espiritual y temporal hasta el tiempo presente. México, 1936, pp. 47-61. Sobre los avatares del manuscrito, véase Mathes, M., "Miguel Venegas, protohistoriador de las Californias", Calafia. Revista de la Universidad Autónoma de Baja California, V, 2 (1984), pp. 11-20. 
la "Descripción de la California y sus habitantes", y dentro de la misma, el capítulo cuarto se titula "De los animales, aves, insectos, árboles, frutas, plantas, minerales, peces, conchas y placeres de perlas de la California y sus mares". Sin embargo, los autores no pasan de una enumeración de los distintos productos del territorio y de los animales y plantas que en él vivían. No se olvidaron de destacar la importancia de una singular planta, la pitahaya, desconocida en otros lares: "sus ramas son a manera de Cirios histriados, que salen derechos a lo alto desde su tronco, de suerte que hacen su copa muy vistosa: no llevan hoja alguna y en esas mismas ramas nace pegada su fruta". Además de ser el principal alimento de los naturales, eran muy estimadas por sus propiedades contra el mal de loanda ${ }^{15}$.

Para completar la historia natural de California, informar sobre los sucesos posteriores ocurridos en la península hasta la expulsión de los jesuitas en 1767 y rectificar ciertas afirmaciones vertidas en el libro de los padres Venegas y Burriel, otro misionero, Miguel del Barco, aprovechó su largo destierro en Italia para clasificar y exponer lo observado durante más de treinta años de misionero en Baja California. Uno de los resultados de su labor fue una notable descripción de las características geográficas y fisiográficas de la península, que ordenó en once capítulos: I. Animales montaraces; II. De los insectos y reptiles; III. De las aves; IV. Árboles de naturaleza regular; V. De los árboles de naturaleza irregular; VI. De los arbustos, matas y hierbas; VII. Del trigo de California; VIII. De los mescales y algunas raíces; IX. De los peces; X. De los testáceos; y XI. De los minerales, salinas y piedras. Es interesante la división que realiza, estudiando a los peces y testáceos tras hablar del reino vegetal, cuyos capítulos están precedidos de los dedicados a los animales terrestres y a las aves. No se olvida de los minerales, pero sólo les dedica un capítulo ${ }^{16}$.

La obra del padre Barco es muy rica en información, reunida gracias a una paciente observación y memoria. Cataloga y describe numerosos árboles y frutos, ofreciendo en varias ocasiones su nombre indígena y adjuntando sus propiedades farmacopeas. Dedica un capítulo a los problemas que tenía la adaptación del trigo en California y se detuvo en el empleo de las semillas, los mezcales y las pitahayas en la dieta indígena. También Barco resaltó las propiedades medicinales de la jojoba, incluyendo un recetario impreso en México el año $1749^{17}$, y en cuanto a los animales, incluye una curiosa descripción del pez mulier o nereides, atribuida al padre Victoriano Arnés, acompañada de un dibujo: "El pez mulier en la figura de una mujer de medio cuerpo arriba; y de pescado común, de medio cuerpo abajo. Como lo hallamos seco y aplastado como un bacalao, no se pudo hacer mucha anatomía. No obstante, aparecía la

15. Venegas, Noticias de la California, pp. 55-56.

16. Miguel del Barco, Historia natural y Crónica de la Antigua California. Edición y estudio preliminar de Miguel León-Portilla, México, 1973.

17. Las "Virtudes de las Jojobas" se encuentran en Barco, M., Historia natural, pp. 96-97. 
cara, cuello, hombros y pecho blanco, como si llevara una costilla y tuviera descubierto los pechos; aunque no me acuerdo si se distinguían los pezones. Lo demás estaba cubierto de escamas y remataba en colas como otros peces. Su grandor será como de dos palmos, y a proporción de ancho, a semejanza del bacalao. No se descubrían brazos ni cabello. Le hallamos en la playa en diámetro opuesto a mi misión de Santa María, en el mar del Sur, en una ensenada que se forma al fin del arroyo llamado Catabiñá"18.

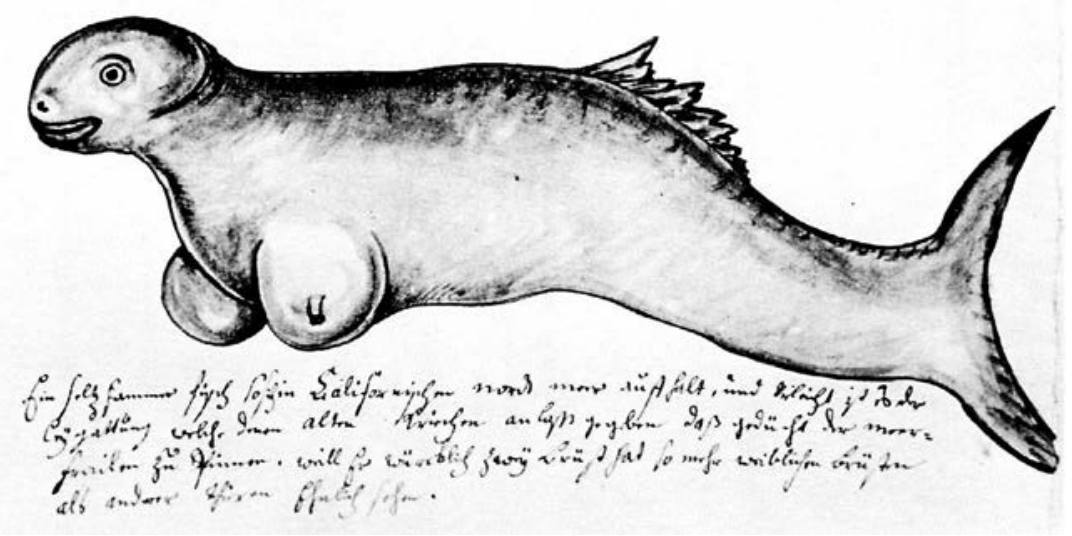

Imagen 3. Pez mulier o nereides. Dibujo de Ignacio Tirsch, S.J. Circa 1767. Biblioteca Nacional de Praga.

Otro jesuita expulsado, el padre Miguel Baegert, decidió contar la verdad -su verdad- de California ante los numerosos errores que circulaban en los libros europeos. Su visión fue muy crítica, impregnada de gran pesimismo, pero nos legó un colorista relato fruto de los diecisiete años que estuvo en la península, la mayoría del tiempo como responsable de la árida y pobre misión de San Luis Gonzaga. La primera parte de su obra, titulada, como ya señalamos anteriormente, Noticias de la península americana de California (Mannheim, 1772), está dedicada a la historia natural. El guión elaborado por el padre es como sigue: I. De la posición, longitud, latitud y extensión de California, así como del Golfo de California; II. Del calor, del frío y de las cuatro estaciones del año en California; III. De la lluvia y otras aguas en California; IV. De las cualidades, fertilidad y aridez de la tierra en California; V. De los matorrales y espinas; VI. De las frutas de California; VII. De los cuadrúpedos, pescados y aves en California; VIII. De las sabandijas de California; y IX. De las minas y perlas en California.

18. Barco, M., Historia natural, p. 128. 


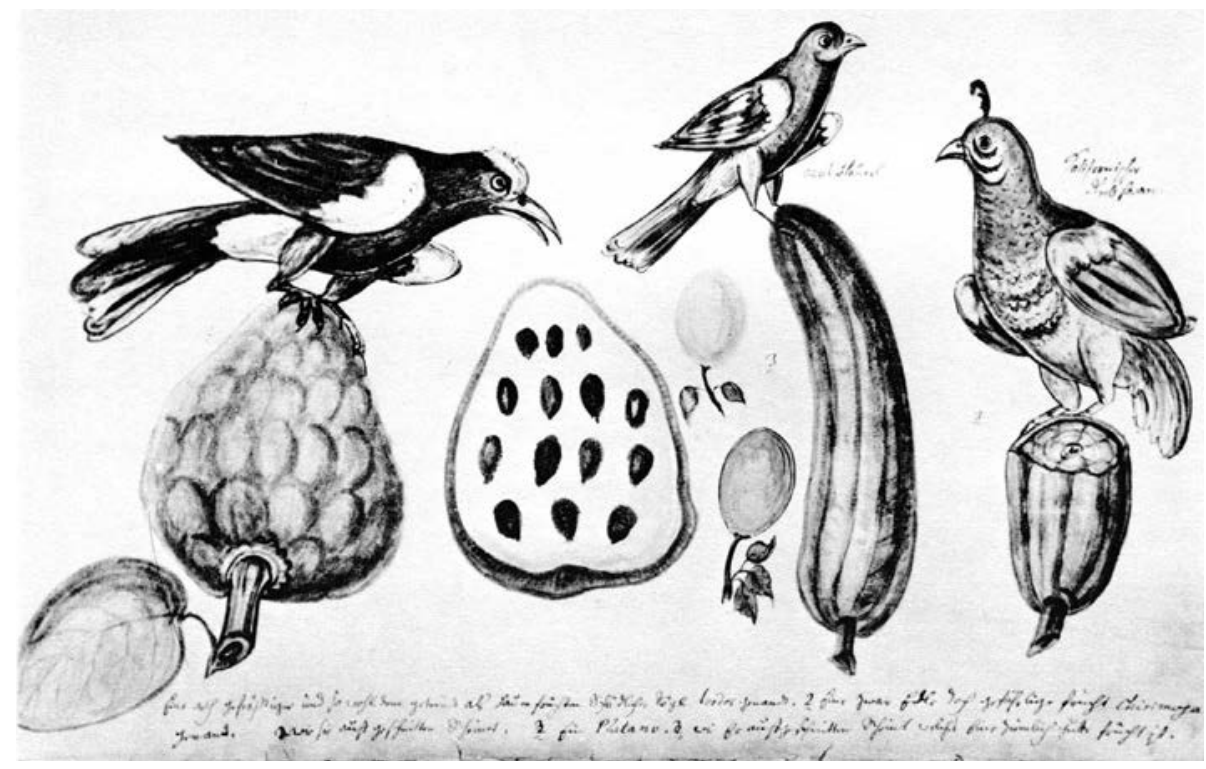

Imagen 4. Pájaros y frutos de la Baja California. Dibujo de Ignacio Tirsch, S.J. Circa 1767. Biblioteca Nacional de Praga.

Nuevos capítulos sobre historia natural y geografía de la Baja California fueron escritos por el famoso jesuita Francisco Javier Clavijero en su Historia de la Antigua o Baja California, publicado en Venecia en 1789. Clavijero nunca estuvo en California, basando su libro en las informaciones de otras obras anteriores y en informaciones directas que logró en conversaciones con antiguos misioneros, compañeros entonces del destierro. Hay que destacar la clasificación que hace de las plantas por su utilidad -concepto central del pensamiento ilustrado- y la larga lista de peces que ofrece a sus lectores: Libro Primero. I. Situación y nombre de la California, sus puertos, cabos e islas en ambos mares; II. Terreno y clima; III. Montes, piedras y minerales; IV. Vegetales y su división; V. Plantas nativas de la California útiles por su fruto; VI. Plantas extranjeras; VII. Plantas útiles por sus hojas; VIII. Plantas útiles por su tronco o tallo; IX. Plantas útiles por su raíz; X. Plantas útiles por su jugo o goma; XI. Plantas nocivas y extravagantes; XII. Insectos; XIII. Reptiles; XIV. Peces; XV. Aves; XVI. Cuadrúpedos [...] Al igual que otros jesuitas expatriados, Clavijero quiso desterrar las numerosas falsedades que, acerca de la California, recorrían Europa ${ }^{19}$.

19. Clavijero, F. X., Historia de la Antigua o Baja California. Edición de Miguel León-PortiIla, México, 1969, pp. 9-48. 
La única crónica dominica que ha llegado hasta nosotros, las Noticias de la provincia de Californias del dominico valenciano Luis de Sales (Valencia, 1794), muestra menos interés por la historia natural peninsular. Las noticias son tan escuetas como interesantes, echando el misionero en falta hombre doctos que ayudasen a reconocer científicamente la península: "Asimismo hay muchas plantas medicinales de que yo mismo me he valido para tabardillos, llagas, dolores de costado y otras enfermedades. Si hubiera por esta provincia hombres curiosos y dedicados al examen de dichas yerbas, podrían libertar la naturaleza de varios insultos..."20.

\section{Los científicos del desierto}

La expulsión de los jesuitas de la Baja California planteó un serio problema a las autoridades virreinales, quienes pronto buscaron sustitutos para continuar la labor misional. Además, la Corona se mostró muy interesada en aumentar el control sobre la citada península y en potenciar la economía y el desarrollo del franco occidental de la Nueva España con el fin de impedir el asentamiento de otras naciones extranjeras -especialmente rusos e ingleses-, y aumentar la capacidad defensiva de aquellos parajes, al menos durante los primeros años después de la salida de la Compañía de Jesús. Numerosas iniciativas fueron realizadas, gran parte de ellas gracias a la incansable voluntad del visitador José de Gálvez, quien viajó a la Baja California en el verano de 1768 acompañado de un importante séquito, en el que se contaban varios científicos relevantes. Incluso llegó a dejar a su salida a uno de ellos, el mexicano Joaquín Velázquez de León, como lugarteniente ${ }^{21}$.

Las labores de este científico criollo se centraron en la mejora del funcionamiento y rendimiento de las minas bajacalifornianas, si bien, tras finalizar sus trabajos, fue acusado de haber puesto en marcha varias novedades tecnológicas y experiencias que en nada favorecieron a la minería local. Por el contrario, sus trabajos habrían servido para arruinar la minería al convertir Velázquez las modestas instalaciones en un laboratorio para probar sus nuevos inventos, que más tarde trasladaría a la minería novohispana gracias a su elección como director del Tribunal de Minería ${ }^{22}$.

Velázquez de León participó, al igual que Gálvez, de una visión positiva sobre las riquezas y el futuro de la California. Sólo había que encontrar a los administradores y las medidas adecuadas para potenciar su desarrollo. El primer

20. Sales, L., Noticias de la provincia de Californias en tres cartas de un sacerdote religioso, hijo del real convento de predicadores de Valencia, a un amigo suyo. Madrid, 1960, p. 25.

21. Sobre este interesante científico, véase Moreno de los Arcos, R., Joaquín Velázquez de León y los trabajos científicos sobre el Valle de México, 1773-1775, México, 1977.

22. Sobre el tema, véase Amao Martínez, J. L., Mineros, misioneros y rancheros de la Antigua California. Madrid, 1997. 
paraje elegido para actuar fueron las pequeñas exploraciones mineras que Manuel de Ocio e Ignacio de Mena habían levantado con grandes dificultades y la constante oposición de los jesuitas. Durante su breve estancia, Gálvez redactó varios reglamentos y órdenes para mejorar las condiciones de los mineros y rebajar el precio de productos básicos como el azogue y la pólvora. Por su parte, Velázquez se hizo cargo de la hacienda de beneficio que Manuel de Ocio tenía en el Real de Santa Ana, tras su adquisición por el Visitador, e inició varias reformas. Fruto de sus experiencias en la península fue el informe que presentó al virrey Marqués de Croix el 9 de febrero de 1771, todavía inédito. Consta de 37 folios y fue acompañado de ocho estampas de máquinas, hornos y otras novedades ensayadas en la minería bajacaliforniana.

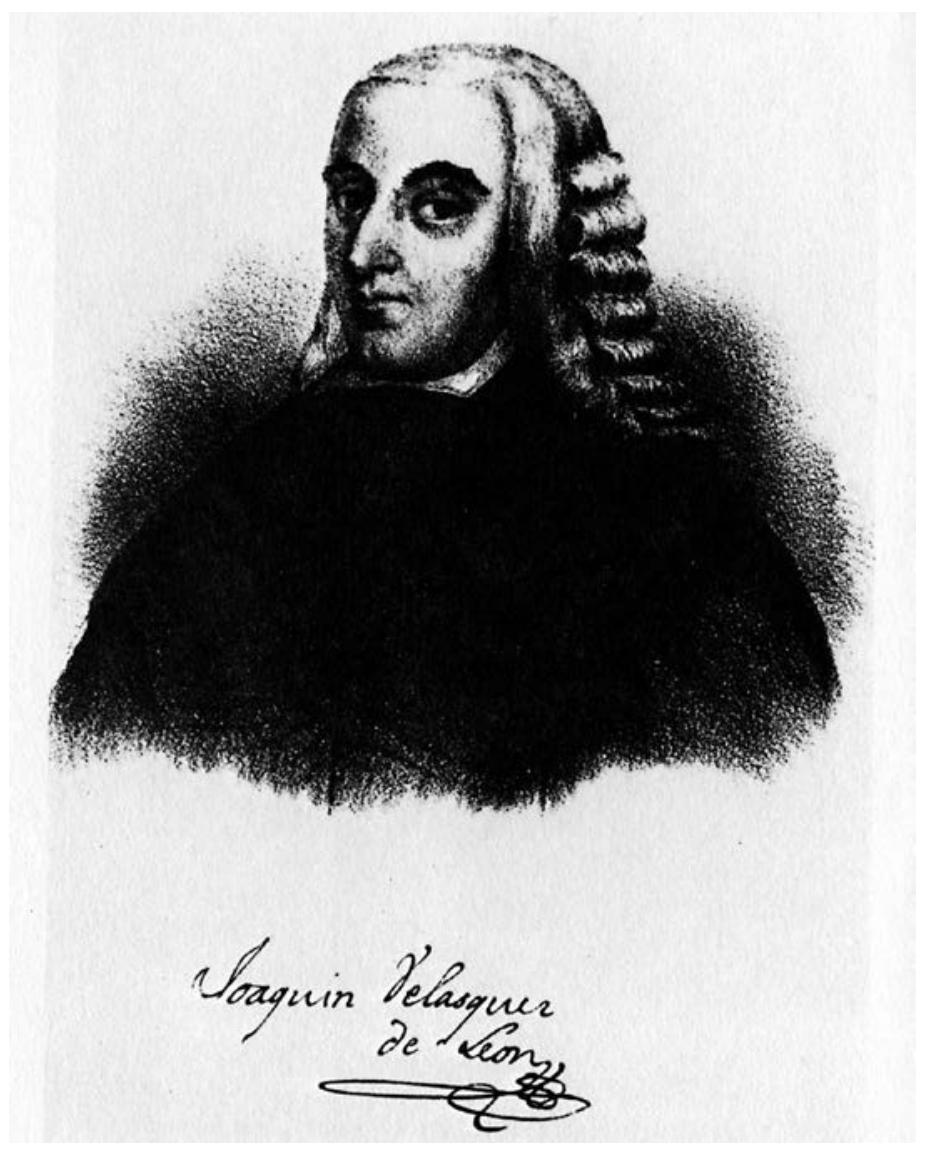

Imagen 5. Grabado de Velázquez de León, incluido en la obra Estudio Biográfico del Señor Don Joaquín Velásquez Cárdenas y León, de Santiago Ramírez, México, 1888. 
Velázquez de León analizó tres aspectos: la búsqueda de las vetas, la extracción de los metales y el beneficio de los minerales, asunto, éste último, que ocupó la mayor parte del informe. El científico criollo criticó las numerosas deficiencias que abundaban en la pobre minería bajacaliforniana, modificó el horno de fundición y el clásico mortero "de a caballo", e introdujo mejoras en el método de cocimiento o del cazo. Otros inventos no pudo ponerlos en práctica por la pobreza de medios ${ }^{23}$. En general, la labor de Velázquez fue muy criticada por las autoridades, los misioneros franciscanos y los antiguos propietarios de las minas, si bien, es difícil de evaluar el total de los daños y los beneficios resultantes de su paso por la Baja California.

Hay que resaltar que nos encontramos ante una experiencia científica al servicio de la ciencia "colonial", gracias a la cual se pudieron ensayar diversas medidas que luego fueron beneficiosas para el resto de la Nueva España. Pero pasemos a otro tema. Durante la estancia del científico criollo en la península llegó una expedición franco-española destinada a medir el Paso de Venus por el disco del Sol. Velázquez de León ofreció su colaboración, pero sus colegas europeos le recomendaron que midiese por separado el Paso de Venus desde el real de Santa Ana, donde residía. De esta forma, ciencia metropolitana y ciencia colonial se dieron la mano en la lejana península.

La expedición astronómica hispano-francesa comisionada para observar el Paso de Venus por el disco del Sol en la lejana península bajacaliforniana estuvo encabezada por el científico francés Jean Baptiste Chappe d'Auteroche, contando entre sus miembros con los guardiamarinas españoles Salvador de Medina y Vicente Doz ${ }^{24}$. Fue, sin duda, el acontecimiento científico más importante que tuvo lugar en la Baja California durante la centuria ilustrada, pues incorporó a los lejanos parajes californianos dentro de los planes científicos de la Europa de las Luces, ya que los datos obtenidos por los comisionados españoles y franceses, y por el mexicano Velázquez de León, se contaron entre los más perfectos de los realizados durante el tránsito del planeta Venus el año 1769.

La expedición llegó al puerto de Veracruz el 8 de marzo de 1769 y, tras una breve estancia en la capital mexicana, sus miembros se dirigieron directamente al puerto de San Blas, desde donde alcanzaron la Baja California a bordo del paquebot La Concepción. A finales de mayo se iniciaron los trabajos para levantar sendos observatorios: uno español y otro francés, que estuvieron pronto listos para dar comienzo a las pruebas de rigor. Por fin, el 3 de junio, los expedicionarios pudieron observar el esperado fenómeno astronómico con toda claridad, si bien sus resultados fueron distintos. Pocos días después, los expedicionarios empeza-

23. Bernabéu Albert, S., "Ciencia y Minería en Baja California: el informe de Joaquín Velázquez de León", Asclepio. Revista de Historia de la Medicina y de la Ciencia, XXXIX, 2 (1987), pp.103-122.

24. Bernabéu Albert, S., "La comisión española en la expedición Chappe d'Auteroche", Ciencia, Vida y Espacio en Iberoamérica, Madrid, 1987, vol. 3, pp. 17-35. 
ron a sentir los primeros síntomas de una epidemia de tifus que asolaba el sur de la península aquel año. Chappe d'Auteroche enfermó el 11 de junio, tras haber realizado otras observaciones complementarias de Júpiter y el Sol. Finalmente, el 1 de agosto murió el célebre científico francés, siendo enterrado en la misión de San José del Cabo. La misma suerte correrían otros miembros de la expedición, como el guardiamarina español Salvador de Medina, quien falleció en el puerto de San Blas pocos días después de desembarcar de vuelta de la península ${ }^{25}$.

Otro científico del desierto fue un naturalista riojano, integrante de la expedición botánica de Martín de Sessé y José Mariano Mociño, conocida como La Real Expedición Botánica a Nueva España (1787-1803), Ilamado José Longinos Martí$n e z^{26}$. Diversos enfrentamientos con el jefe de la expedición le obligaron a realizar sus actividades científicas por separado, e incluso a pedir permiso al Virrey para realizar una expedición individual a lo largo de la Nueva y de la Vieja California. Otro miembro díscolo de la expedición botánica le acompañaría (el farmacéutico Jaime Senseve), si bien pronto abandonó la jornada californiana aduciendo retrasos en su salario, de forma que Longinos tuvo que acometer la nueva empresa en solitario. El 20 de enero de 1791 partió de México y durante el verano alcanzó algún punto de la península. Durante los siguientes meses reconoció la península hasta llegar a las nuevas misiones franciscanas del Norte. Sus observaciones y comentarios fueron recogidos en un diario, que entregó al virrey Revillagigedo, en el que anotó las producciones de los distintos parajes visitados y apuntó sus beneficios para el Estado y para el desarrollo del comercio ${ }^{27}$.

Los resultados científicos fueron muy positivos. José Longinos aseguró al virrey haber recolectado más de treinta cajas de especímenes, para lo cual contó con la ayuda de diversos comisionados indios. Longinos listó los productos californianos capaces de ser explotados comercialmente y compiló numerosas plantas medicinales, comentando los varios usos que encontró en su periplo. Otro asunto que el naturalista riojano recogió fueron sus impresiones sobre el petróleo, la brea y otras sustancias volcánicas que halló cerca de la misión de San Gabriel (Los Ángeles). Nuestro expedicionario terminó su viaje en Monterrey, desde donde regresó a San Blas el 22 de noviembre de 1792.

La última expedición ilustrada fue la comandada por Gonzalo López de Haro, experimentado marino del Noroeste y comandante de San Blas en varias ocasiones. Haro, natural de Cantabria, era alférez de fragata de la Real Armada y primer

25. Bernabéu Albert, S., Las huellas de Venus. El viaje del astrónomo Chappe d'Auteroche a Nueva España (1768-1769), México, 1998. Recientemente se ha editado una edición facsimilar, D'Auteroche, Chappe, Voyage en Californie pour l'Observation du Pasaje de Vénus sur le disque du Soleil. México, 2004.

26. Maldonado Polo, J. L., De California a El Petén: el naturalista riojano José Longinos Martínez en Nueva España. Logroño, 1997.

27. Bernabéu Albert, S., "Diario de las expediciones a las Californias" de José Longinos. Aranjuez, 1994. 
piloto de número cuando se le ordenó reconocer, examinar y cartografiar la costa pacífica de la península californiana desde el puerto de San Diego al Cabo de San Lucas. El viaje comenzó en San Blas el 22 de abril de 1803, anclando en el puerto de San Diego el 15 de junio tras una travesía sin incidentes. En este puerto altacaliforniano inició los trabajos científicos, que continuó el 3 de julio rumbo al sur, observando las latitudes y longitudes, dibujando las costas, observando las corrientes y mareas, y escribiendo un diario hasta el 31 de octubre, fecha en la que regresó al puerto de San Blas ${ }^{28}$. Fruto también de la expedición fueron varios mapas que rectificaron numerosos errores de otros anteriores y que hoy se guardan en varios repertorios documentales de México y España. Una muestra del buen hacer de Haro es la siguiente descripción del puerto de San Quintín:

"El puerto de San Quintín es sumamente conocido a larga distancia, pues viniendo corriendo la costa por la parte del norte o por cualesquiera punto en donde recalare, sobre él se ven cinco cerros bastante elevados e interpolados con otros muy pequeñitos, y todos separados unos de otros, hallándose estos situados en el frontón del norte de adentro del puerto, no pudiéndose estos confundirse con otros algunos por ser los únicos que hay en toda esta costa, pues a la larga distancia de ellos corre la serranía muy unida y elevada. [...] El referido puerto está todo lleno de bajiales con un banco de arena próximo a su entrada y la mayor parte rodeado de méganos de arena, interpolados en ella muchos inútiles ramajos salitrosos; no se encuentra en todo él peces más que unos Ilamados rayas y tiburones, lobos marinos y nutrias, sin agua ni arboleda para hacer leña, y para proveerse de estos dos urgentes y necesarios renglones o de otros es preciso ocurrir a los auxilios de los padres misioneros que se hallan distante diez leguas en la misión de Santo Domingo..." ${ }^{\prime 29}$.

El marino tuvo varios encuentros con los misioneros dominicos, obteniendo privilegiadas informaciones, como la existencia de una nao filipina en la punta Peligrosa:

"Según noticias de los padres misioneros de estas misiones de la(s) fronteras, se halla en la referida punta Peligrosa un buque grande enterrado en las arenas de la playa, y en las mayores bajamares se descubren los fragmentos que han quedado de él y los indios de la misión de San Borja y de las inmediatas a ésta han escarbado sobre él y han sacado muchos panes

28. López de Haro, G., "Diario de la navegación que ejecutó el alférez de fragata y primer piloto del número de la Real Armada Don ..., comandante de la balandra Horcasitas, que de orden del excelentísimo señor virrey de Nueva España Don José de Iturrigaray salió de San Blas el 22 de abril del año de 1803 con el objeto de reconocer, examinar y levantar los planos de la costa del Noroeste de la Antigua California comprendida desde el puerto de San Diego hasta el Cabo de San Lucas". Archivo General de la Nación, México, Historia, 528, ff. 38r-79v.

29. López de Haro, G., "Diario de la navegación ...", ff. 48r-48v. 
de cera virgen, loza de China y un tejo de oro marcado, por lo que se infiere que dicho buque sería la nao de Manila que antes de la conquista de dichas misiones hubo noticias haber naufragado sobre el puerto de San Francisco de la Nueva California, comprobándose ser esto cierto, pues salió de Manila una embarcación y se dirigió a dicho puerto con el fin de ver si descubría sobre su costa algunos fragmentos de ella y no encontraron nada, por lo que es probable ser la referida nao la que se halla sumergida en la indicada punta Peligrosa" ${ }^{30}$.

El viaje estuvo precedido por numerosas visitas de barcos extranjeros a las costas peninsulares, la captura de varios desertores y la declaración de guerra entre España y Rusia (octubre de 1799). Los buenos oficios de Haro le llevaron años más tarde a fijar los límites exactos de las provincias de Texas y Luisiana (1808), empresa a la que dedicó varios años ${ }^{31}$.

\section{La ciencia y el encubrimiento de California}

Las expediciones científicas siguieron visitando California durante el siglo XIX y el XX. Aún hoy es objeto de renovado interés científico e histórico, pero tan sólo me interesa destacar, para finalizar, la labor desarrollada por diversos científicos en estos lejanos parajes durante la centuria ilustrada con el fin de ofrecer un ejemplo del interés de la ciencia por la frontera, allí donde el Imperio terminaba. Regiones que había que conocer mejor, explotar y consolidar para impedir que otras naciones se adueñaran de ellas y cuyos secretos naturales eran poco conocidos. No todas las experiencias fueron positivas y-como al principio señalábamos- a menudo coincidieron intereses metropolitanos con coloniales. Los participantes en estos episodios procedían de diversos campos científicos: varios fueron misioneros, otros profesores y guardiamarinas, llegando alguno de ellos a ser una figura estimada por sus contemporáneos, como fue el caso de Clavijero y Chappe d'Auteroche. Todos ellos pusieron su grano de arena, si bien sus hallazgos no tuvieron la trascendencia debida.

Todas estas aportaciones científicas nos permiten, además, reflexionar sobre un modelo de actividad científica tan alejada de la ciencia colonial como de la metropolitana, que bauticé hace algunos años como "ciencia de la frontera", que completaría el papel de la ciencia en la historia de la expansión imperial. La frontera -los bordes del Imperio- se convertiría, así, en patrocinadora de la

30. López de Haro, G., "Diario de la navegación ...", f. 59r.

31. Existen unas "Memorias para la Historia Natural de California escritas por un religioso de la provincia del Santo Evangelio de México. Año de 1790", en el Archivo General de la Nación, cuya autoría todavía está en duda. Otros exploradores de la península contribuyeron poderosamente a conocer la península, si bien el origen de esos periplos no fue "ilustradamente" científico. Eso no impide, por supuesto, reconocer sus labores, aunque debería de ampliar los fines de este breve trabajo para estudiarlos con más detalle. 


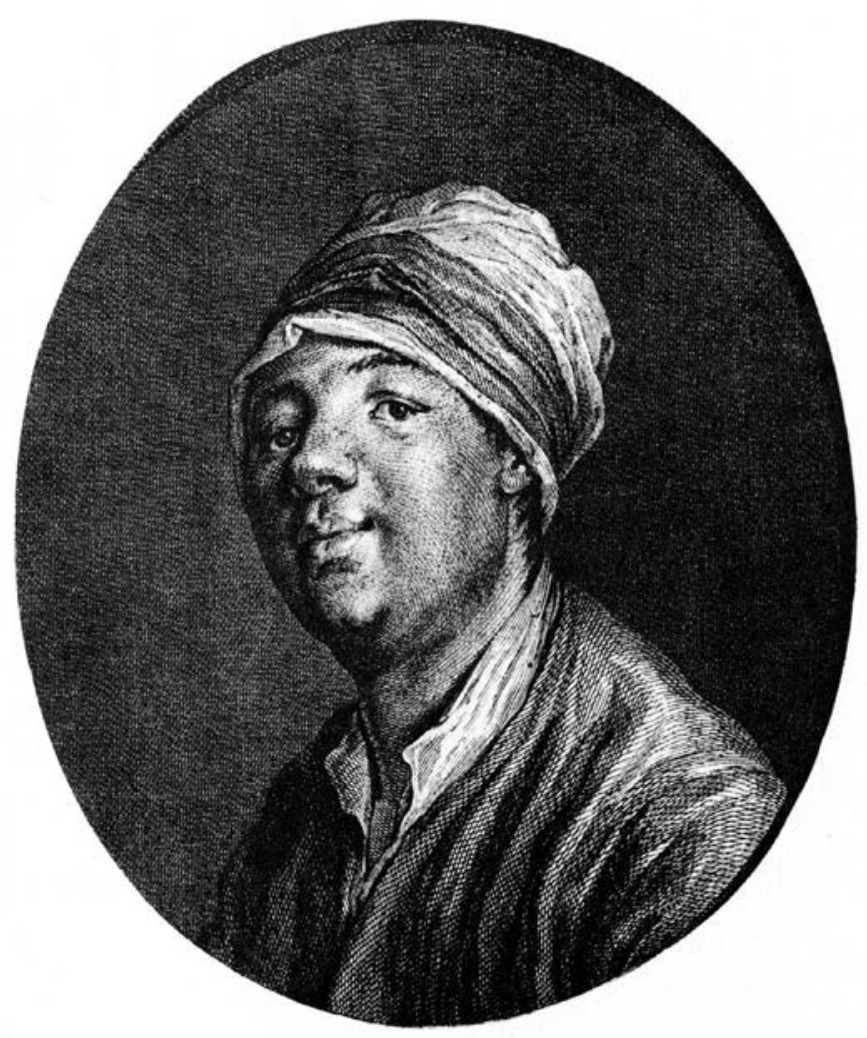

Imagen 6. Retrato de Jean-Baptiste Chappe d'Auteroche. En The 1769 Transit of Venus, Los Ángeles, 1982.

actividad de los científicos, retando las concepciones establecidas y convirtiéndose en laboratorio en donde ensayar nuevas tecnologías. La frontera sería el último espacio de la ciencia, en donde conviviría la tecnología de punta con las concepciones más obsoletas, y las experiencias al servicio de las instituciones europeas con las enviadas por la capital mexicana ${ }^{32}$.

La ciencia es aquí "transitoria" y "frugal", lejos de las instituciones científicas y de los grandes debates. El principal protagonista es el espacio: un trozo del planeta al que se quiere conocer y utilizar. En último extremo, de forma pasiva o activa, se buscan perseverantemente sus datos para confirmar y elabo-

32. Repito aquí las conclusiones a las que llegué en otro trabajo anterior, Bernabéu Albert, S., "Los científicos del desierto. Ciencia y técnica en Baja California". Revista de Indias, LI, 192 (1991), pp. 419-429. 
rar teorías científicas y probar nuevas tecnologías ${ }^{33}$. Esta sería una importante contribución de la Ilustración al conocimiento de la península, si bien su imagen y sus pobladores originales serían desfigurados por los anteojos de la razón, que repensó un mundo "a escala europea", al servicio de la "inteligencia" europea. California ... siempre en el espejo.

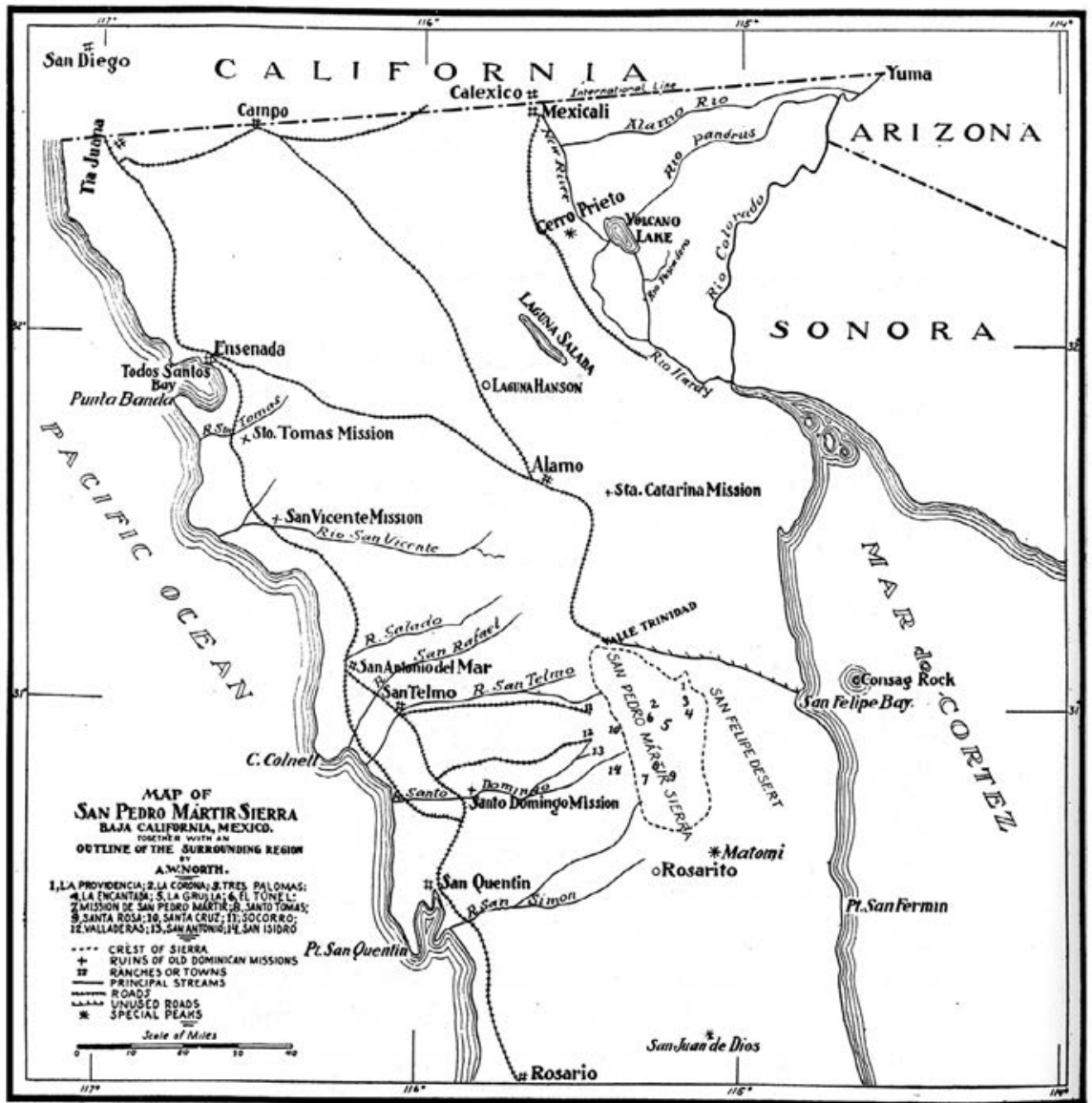

Imagen 7. Mapa de la Sierra de San Pedro Mártir. Incluido en la obra de Arthur W. North, Camp and Camino in Lower California, New York, 1910.

33. Dos visiones necesarias, que complementarían la que aquí defendemos, surgirían al insertar la Baja California en la "ciencia" del Pacífico (MacLeod, R. and Rehbock, P. F., eds., Nature in Its Greatest Extent. Western Science in the Pacific. Honolulu, 1989) y en la expansión marítima hacia el Noroeste de América (Bernabéu Albert, S., "España en el Noroeste. Navegantes y proyectistas en el siglo XVIII", Nootka. Regreso a una historia olvidada. Madrid, 1998, pp. 15-25). 
Empezamos este capítulo en Roma, durante una elegante función de ópera. Lo acabaremos en las sierras de San Pedro Mártir. Durante una subida a la sierra, el riojano José Longinos conoció el temor de algunos de sus porteadores indígenas por un paraje concreto, que llamaban el "Agua Grande", pues en ella había peces. Sigue narrando el naturalista riojano que:

"Al tiempo que llegué a verla, los cristianos nuevos y gentiles amigos de la escolta, con otros que se habían agregado, se fueron quedando atrás y poniéndose en los parajes más altos, donde podían ver nuestra llegada a la laguna, pensando ellos nos verían ir cayendo muertos. No obstante la firme confianza que yo tenía de que era alguna creencia misteriosa de sus hechiceros, por si tenía algún origen de ser agua mineral o impregnada de algunas partículas capaces de haber hecho morir (a) alguno, no dejé a los soldados de mi escolta la probasen hasta estar analizada. En efecto, hice esta operación y vi era de las aguas más ricas que se pueden beber, como que tenía su origen de unos montes sin el menor átomo de mineral. Luego, bebimos todos de ella y a fuerza se les hizo llegar a los neófitos y gentiles, haciéndoles beber y bañarse en testimonio de su engaño. Los animales que decían como que al pasar de lejos sólo darían alguna mirada, se les figuraron algunos palos que había en la laguna. Este entusiasmo y otros que veneraban a un cerro elevado que había cerca de esta laguna, diciendo que, el que comía, dormía o hacía sus necesidades de espalda, luego se moría, se les quitó esta creencia haciéndoles presentasen el trasero descubierto al dicho cerro en señal de desprecio de sus falsas creencias; y con el desengaño de su Agua Grande, ya costó poco trabajo reducirlos (de) aquel desacato de veneración".

Longinos dirigió este otro gesto teatral, en donde la ciencia desterraba las creencias indígenas. A pesar de lo chistoso del episodio, quizás la ciencia ilustrada estaba cumpliendo con su cometido principal y más noble: el desterrar las supersticiones. Una empresa que todavía queda por concluir en gran parte de la frontera norte de México. 